\title{
Selectivity and Priority on Inclusion of Amylose toward Guest Polyethers and Polyesters in Vine-Twining Polymerization
}

\author{
By Yoshiro KANEKO, Koutarou BEPPU, Tsuyoshi KYUTOKU, and Jun-ichi KADOKAWA*
}

In this paper, we describe that amylose selectively includes poly(tetrahydrofuran) (PTHF) or poly $(\delta$-valerolactone) (PVL) from a mixture of two resemblant polyethers, i.e., poly(oxetane) (POXT) and PTHF, or a mixture of two resemblant polyesters, i.e., PVL and poly( $\varepsilon$-caprolactone) (PCL) in vine-twining polymerization. These selective inclusions were achieved by the formation of amylose-polymer inclusion complexes in phosphorylase-catalyzed enzymatic polymerization of $\alpha$-D-glucose 1-phosphate from maltoheptaose as a primer in the presence of mixtures of POXT/PTHF and PVL/PCL, respectively. In addition, we evaluated the priority on inclusion of amylose toward these guest polymers in the vine-twining polymerization method to be PTHF > PVL > POXT > PCL.

KEY WORDS: Amylose / Enzymatic Polymerization / Inclusion Complex / Phosphorylase / Vine-twining Polymerization /

Biological macromolecules such as proteins, nucleic acids, and polysaccharides precisely discriminate various molecules in vivo, for example single strand of DNA recognizes homology in duplex one. ${ }^{1}$ Such a recognizability of the biomolecules has been often applied to discrimination of artificial compounds. For example, it has been reported that peptides recognized the specific structures of synthetic polymers. ${ }^{2}$ We have also continuously been investigating the recognizability of amylose, a natural polysaccharide, toward synthetic polymers by means of its inclusion in amyloseforming polymerization field that is described as follows. ${ }^{3}$

Amylose has helical conformation linked through $(1 \rightarrow 4)-\alpha$ glycosidic linkages and is a well-known host compound that forms inclusion complexes with slender compounds having relatively lower molecular weight such as fatty acids by noncovalent interaction between guest molecules and the cavity of amylose. ${ }^{4}$ However, little has been reported regarding the formation of inclusion complexes between amylose and polymeric compounds. ${ }^{5}$ The main difficulty in incorporating polymeric compounds into the cavity of amylose is that the driving force for the binding is only caused by hydrophobic interactions. Amylose, therefore, does not have sufficient ability to include the long chains of guest polymers into its cavity.

By means of the enzymatic method for direct construction of the polysaccharides, ${ }^{6}$ we have developed a new methodology for the preparation of inclusion complexes composed of amylose and synthetic polymers, ${ }^{3}$ which was achieved by the enzymatic polymerization forming amylose in the presence of guest polymers. The representation of this reaction system is similar to the way that vines of plants grow twining around a rod. Accordingly, we have proposed that this polymerization method for the preparation of amylose-polymer inclusion complexes is named "vine-twining polymerization."

As the guest polymers for this polymerization system, hydrophobic polyethers, ${ }^{3 \mathrm{a}, \mathrm{c}}$ polyesters, ${ }^{3 \mathrm{~b}, \mathrm{~d}, \mathrm{i}}$ a poly(ester- ether), ${ }^{3 \mathrm{~d}}$ and polycarbonates ${ }^{3 \mathrm{~h}}$ have been employed to form the corresponding inclusion complexes with amylose. On the basis of the results in the previous studies using these guest polymers, the suitable hydrophobicity of the guest polymers in the vine-twining polymerization has been considered to be a very important factor in whether amylose can include them or not. For example, the followings are the cases using the various polyethers as the guest polymer in vine-twining polymerization. When this polymerization was carried out using the aliphatic polyethers having appropriate hydrophobicities such as poly(oxetane) (POXT, $-\left[\mathrm{CH}_{2} \mathrm{CH}_{2} \mathrm{CH}_{2} \mathrm{O}\right]_{n^{-}}$) and poly(tetrahydrofuran) (PTHF, - $\left[\mathrm{CH}_{2} \mathrm{CH}_{2} \mathrm{CH}_{2} \mathrm{CH}_{2} \mathrm{O}\right]_{n}$-), these hydrophobic polyethers were included in the cavity of amylose to form the inclusion complexes. ${ }^{3 \mathrm{c}}$ However, in addition to no formation of the inclusion complex from poly(ethylene glycol) $\left(-\left[\mathrm{CH}_{2} \mathrm{CH}_{2} \mathrm{O}\right]_{n^{-}}\right)$because of its hydrophilic nature, the preparation of the inclusion complexes has not been achieved from the polyethers with strong hydrophobicity, for example poly(oxepane) (- $\left.\left[\mathrm{CH}_{2} \mathrm{CH}_{2} \mathrm{CH}_{2} \mathrm{CH}_{2} \mathrm{CH}_{2} \mathrm{CH}_{2} \mathrm{O}\right]_{n} n^{-}\right)$, attributed to their aggregation in the aqueous buffer of the solvent for the enzymatic polymerization.

Because these results have inspired us to achieve the selective inclusion toward two resemblant polymers in the vine-twining polymerization by means of slight difference in their hydrophobicities, in the previous communication, we reported that amylose almost selectively included one side of the polyethers, i.e., PTHF from a mixture of POXT/PTHF by this polymerization manner. ${ }^{3 \mathrm{~g}}$ The difference in the chemical structures between POXT and PTHF is only one methylene unit, and those having similar molecular weights were used. Therefore, this system is considered as a tool for precise recognition of the polymers by means of the cavity of amylose. We have continuously investigated the selective inclusion of amylose toward other resemblant polymers, for example polyesters, in the vine-twining polymerization. 
In this paper, we describe the extensive study on the selective inclusion by amylose in the vine-twining polymerization. The employed guest polymers were the polyethers of POXT/PTHF and the polyesters of telechelic poly $(\delta$-valerolactone) (PVL)/telechelic poly( $\varepsilon$-caprolactone) (PCL). In addition, we evaluated the priority on inclusion of amylose toward POXT, PTHF, PVL, and PCL on the basis of the analysis of the products in the vine-twining polymerization using the mixtures of all combinations of two guest polymers chosen among the above-mentioned ones.

\section{EXPERIMENTAL}

\section{Materials}

Phosphorylase was supplied from Ezaki Glico Co. Ltd., Osaka, Japan. ${ }^{7}$ POXT and PTHF were prepared by ringopening polymerization of the corresponding cyclic ethers according to the experimental method reported in previous literature. ${ }^{8}$ PVL and PCL were prepared by ring-opening polymerization of the corresponding lactones initiated with 1,4butanediol catalyzed by scandium(III) triflate according to the experimental method reported in previous literature. ${ }^{9}$ The molecular weights of these polymers were evaluated by means of ${ }^{1} \mathrm{H}$ NMR measurements. Maltoheptaose $\left(\mathrm{G}_{7}\right)$ was prepared by selective cleavage of one glycosidic bond of $\beta$-cyclodextrin under acidic condition. ${ }^{10}$ Other reagents and solvents were used without further purification.

\section{A Typical Procedure for Selective Inclusion of Amylose toward POXT and PTHF ${ }^{3 \mathrm{~g}}$}

A mixture of POXT $\left(M_{\mathrm{n}}=\sim 1800,29.0 \mathrm{mg}=0.5 \mathrm{mmol}\right.$ unit) and PTHF ( $M_{\mathrm{n}}=\sim 1600,36.1 \mathrm{mg}=0.5 \mathrm{mmol}$ unit) was suspended in sodium acetate buffer $(4.5 \mathrm{~mL}, 0.2 \mathrm{~mol} / \mathrm{L}, \mathrm{pH}=$ 6.2) using an ultrasonic wave. After the addition of $\mathrm{G}_{7}$ primer $(0.5 \mathrm{mg}=0.4 \mu \mathrm{mol})$ and $\alpha$-D-glucose 1 -phosphate disodium salt (G-1-P, $30.4 \mathrm{mg}=0.1 \mathrm{mmol}$ ), adjustment of the $\mathrm{pH}$ value to 6.2 using acetic acid aqueous solution $(c a .0 .5 \mathrm{~mL}, 0.2 \mathrm{~mol} /$ L) was carried out. Phosphorylase (16 unit) was added to this solution, and then the solution was stirred vigorously for $6 \mathrm{~h}$ at $40-45^{\circ} \mathrm{C}$. The precipitated product was collected by filtration, washed with acetone and water, and dried under reduced pressure at room temperature to yield $c a$. $7.0 \mathrm{mg}$ of the inclusion complex. ${ }^{1} \mathrm{H}$ NMR $\left(600 \mathrm{MHz}, \mathrm{DMSO}-d_{6}\right): \delta 1.40-$ 1.60 (br, $-\mathrm{CH}_{2} \mathrm{CH}_{2} \mathrm{O}-$ due to PTHF), $\delta$ 1.65-1.72 (br, - $\mathrm{CH}_{2} \mathrm{CH}_{2} \mathrm{O}$ - due to POXT), $\delta$ 3.10-3.92 (m, $\mathbf{H}_{2}-\mathbf{H}_{\mathbf{6}}$ due to amylose, $-\mathrm{CH}_{2} \mathrm{O}-$ due to POXT and PTHF overlapping with HOD), $\delta 4.61,5.44,5.55(\mathrm{OH}), \delta 5.10\left(\mathrm{br}, \mathbf{H}_{1}\right.$ due to amylose).

\section{A Typical Procedure for Selective Inclusion of Amylose toward PVL and PCL (Run 1 in Table I)}

A mixture of PVL $\left(M_{\mathrm{n}}=\sim 830,30.1 \mathrm{mg}=0.3 \mathrm{mmol}\right.$ unit $)$ and PCL $\left(M_{\mathrm{n}}=\sim 930,34.3 \mathrm{mg}=0.3 \mathrm{mmol}\right.$ unit $)$ was suspended in sodium acetate buffer $(4.5 \mathrm{~mL}, 0.2 \mathrm{~mol} / \mathrm{L}, \mathrm{pH}=6.2)$ using an ultrasonic wave, and the following procedures were same as those for selective inclusion toward POXT and PTHF described above. Yield of the product was ca. $6.6 \mathrm{mg} .{ }^{1} \mathrm{H}$ NMR $\left(600 \mathrm{MHz}, \mathrm{DMSO}-d_{6}\right): \delta 1.46-1.70$ (br, $-\mathrm{CH}_{2} \mathrm{CH}_{2} \mathrm{C}(=\mathrm{O})-$ and $-\mathrm{CH}_{2} \mathrm{CH}_{2} \mathrm{OC}(=\mathrm{O})$ - due to PVL), $\delta$ 2.26-2.36 (br, $-\mathrm{CH}_{2} \mathrm{C}(=\mathrm{O})-$ due to PVL), $\delta 3.10-3.92\left(\mathrm{~m}, \mathbf{H}_{\mathbf{2}}-\mathbf{H}_{\mathbf{6}}\right.$ due to amylose overlapping with HOD), $\delta 3.95-4.06$ (br, $-\mathrm{CH}_{2} \mathrm{OC}(=\mathrm{O})$ - due to PVL), $\delta 4.61,5.44,5.55(\mathrm{OH}), \delta 5.10$ (br, $\mathbf{H}_{1}$ due to amylose). The degree of polymerization (DP) values of amylose in the resulting inclusion complexes were calculated by the integrated ratios of the signal of $\mathbf{H}_{\mathbf{1}}$ of amylose chain $(\delta 5.1)$ to the signals of $\mathbf{H}_{\mathbf{1}}(\alpha$ and $\beta)$ of the reducing terminus $(\delta 4.9(\alpha)$ and $4.3(\beta))$ in the ${ }^{1} \mathrm{H}$ NMR spectra (DMSO- $\left.d_{6}-\mathrm{D}_{2} \mathrm{O}\right)$. The DP values were assessed to be $c a$. 59-66, corresponding to $M_{\mathrm{n}}=c a$. 960010700 .

Time-course Experiment for Selectivity on Inclusion of Amylose toward PVL and PCL under the Conditions of Run 6 in Table I

After a mixture of PVL $\left(M_{\mathrm{n}}=\sim 830,30.1 \mathrm{mg}=0.3 \mathrm{mmol}\right.$ unit) and PCL $\left(M_{\mathrm{n}}=\sim 930,34.3 \mathrm{mg}=0.3 \mathrm{mmol}\right.$ unit $)$ was suspended in sodium acetate buffer $(4.5 \mathrm{~mL}, 0.2 \mathrm{~mol} / \mathrm{L}$, $\mathrm{pH}=6.2)$ using an ultrasonic wave, $\mathrm{G}_{7}(13.8 \mathrm{mg}=0.012$ $\mu \mathrm{mol})$ and G-1-P $(30.4 \mathrm{mg}=0.1 \mathrm{mmol})$ were added into the suspension. The following reaction procedures were same as those for selective inclusion described above. After the prescribed reaction time, the reaction solution was lyophilized to obtain a solid mixture and methanol was added to this mixture. Then, methanol-insoluble fraction was isolated by filtration, washed with methanol and acetone, and dried under reduced pressure at room temperature to yield the product.

\section{Evaluation of Priority on Inclusion of Amylose among POXT, PTHF, PVL, and PCL}

A mixture of two guest polymers $(0.3 \mathrm{mmol}$ unit, respectively) chosen among POXT $\left(M_{\mathrm{n}}=\sim 940\right)$, PTHF $\left(M_{\mathrm{n}}=\right.$ $\sim 970)$, PVL $\left(M_{\mathrm{n}}=\sim 830\right)$, and PCL $\left(M_{\mathrm{n}}=\sim 930\right)$ was suspended in sodium acetate buffer $(4.5 \mathrm{~mL}, 0.2 \mathrm{~mol} / \mathrm{L}$, $\mathrm{pH}=6.2$ ) using ultrasonic wave, and the following procedures were same as those for selective inclusion described above.

\section{Measurements}

The ${ }^{1} \mathrm{H}$ NMR spectra were recorded using a JEOL ECA600 and ECX400 spectrometers (JEOL Ltd.). The X-ray diffraction (XRD) measurements were performed at a scanning speed of $2 \theta=2^{\circ} / \mathrm{min}$ using a Geigerflex RAD-IIB diffractometer (Rigaku Co.) with Ni-filtered $\mathrm{CuK} \alpha$ radiation $(=0.15418 \mathrm{~nm})$.

\section{RESULTS AND DISCUSSION}

\section{Selective Inclusion of Amylose toward Two Resemblant Polyethers}

As previously reported, ${ }^{3 \mathrm{~g}}$ the vine-twining polymerization was performed by the phosphorylase-catalyzed enzymatic polymerization of G-1-P $(20 \mathrm{mmol} / \mathrm{L})$ from $\mathrm{G}_{7}(0.08 \mathrm{mmol} /$ L) as a primer ${ }^{6}$ in the presence of a mixture of POXT $\left(M_{\mathrm{n}}=\right.$ $\sim 1800)$ and PTHF $\left(M_{\mathrm{n}}=\sim 1600\right)$ in sodium acetate buffer for 


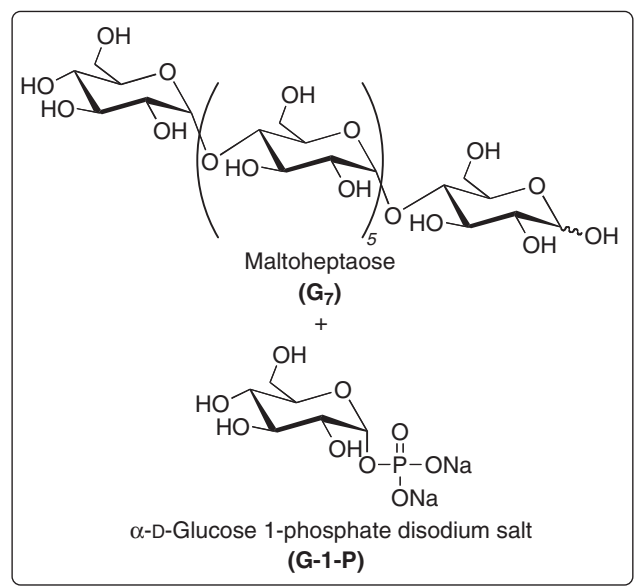

$+$

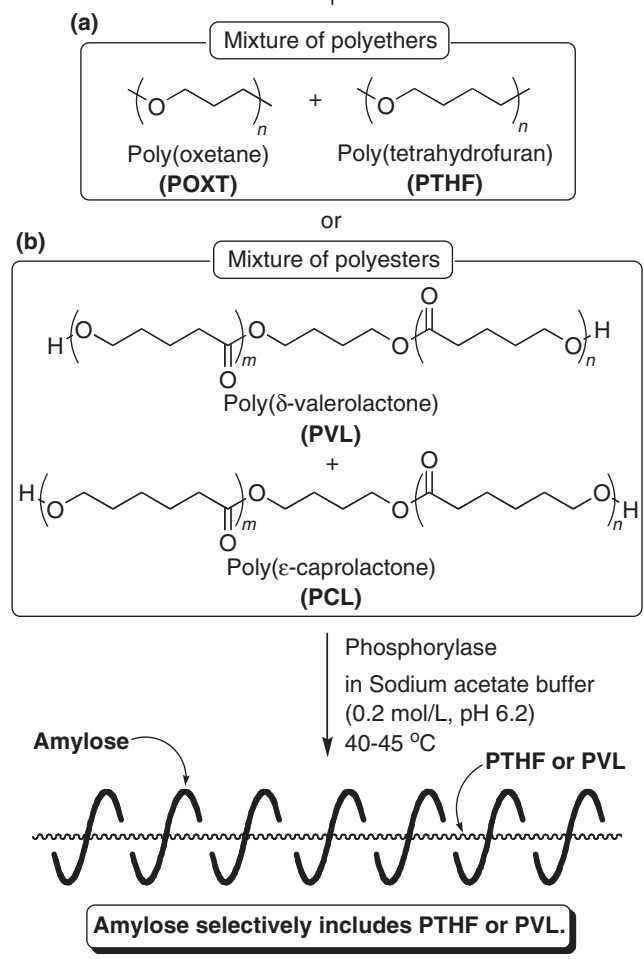

Scheme 1. Selective inclusion of amylose in vine-twining polymerization.

$6 \mathrm{~h}$ at $40-45^{\circ} \mathrm{C}$ (Scheme 1a). The precipitated product was isolated and characterized by the XRD measurement to be the inclusion complex as shown in our previous paper. ${ }^{3}$

The ${ }^{1} \mathrm{H}$ NMR spectrum of the employed mixture of the guest polyethers $\left(\mathrm{CDCl}_{3}\right)$ showed that the unit ratio of POXT/PTHF in feed was assessed to be $0.90: 1.00$ on the basis of the integrated ratio of the signal due to $-\mathrm{CH}_{2} \mathrm{CH}_{2} \mathrm{CH}_{2} \mathrm{CH}_{2} \mathrm{O}-$ of PTHF to the signal due to $-\mathrm{CH}_{2} \mathrm{CH}_{2} \mathrm{CH}_{2} \mathrm{O}$ - of POXT. On the other hand, in the ${ }^{1} \mathrm{H}$ NMR spectrum of the product obtained by the vine-twining polymerization (DMSO- $d_{6}$ ), the signals due to PTHF and amylose were prominently observed and the signal due to POXT slightly appeared (POXT/PTHF $=0.02: 1.00)$. When POXT or PTHF was independently used as the guest for the vine-twining polymerization, the inclusion complex was formed well. ${ }^{3 \mathrm{c}}$ These results indicate that amylose almost selectively includes PTHF from a mixture of the two resemblant polyethers in the vine-twining polymerization. The slight difference in the hydrophobicities of two polyethers probably caused the difference in the inclusion by amylose toward them.

The concentrations of $\mathrm{G}-1-\mathrm{P}$ and $\mathrm{G}_{7}$ in feed strongly affected the selectivity on inclusion of amylose in this polymerization manner. When the vine-twining polymerization was carried out in higher concentrations of G-1-P and $G_{7}$ than those described above, for example 300 and $1.20 \mathrm{mmol} / \mathrm{L}(15$ times), respectively, the unit ratio of $\mathrm{POXT} / \mathrm{PTHF}$ in the products was increased $(0.21: 1.00)$ upon increasing the yields of the products ( $c a .20$ times; $137.1 \mathrm{mg}$ ).

\section{Selective Inclusion of Amylose toward Two Resemblant Polyesters}

An attempt of the selective inclusion by amylose in the vinetwining polymerization was also made in the system using the resemblant polyesters. As described above, the hydrophobicity of the guest polymers in the vine-twining polymerization is a very important factor in whether amylose can include them or not. So far, we reported that the polyesters having appropriate hydrophobicity, i.e., PVL and PCL were included in the cavity of amylose by the vine-twining polymerization. ${ }^{3 \mathrm{~d}}$ However, since the difference in the inclusion by amylose toward these two hydrophobic polyesters with resemblant chemical structures has not been investigated in detail, we examined the selective inclusion of amylose toward PVL and PCL in the vine-twining polymerization. The difference in the chemical structures between PVL and PCL is only one methylene unit and those having the similar molecular weights were used in this study. In addition, when PVL or PCL with appropriate molecular weight $\left(M_{\mathrm{n}}=\sim 1000\right)$ was independently used as the guest polymer for the vine-twining polymerization, the inclusion complex was formed well. ${ }^{3 \mathrm{~d}}$

The selective inclusion of amylose toward two resemblant polyesters was performed by the vine-twining polymerization in the presence of a mixture of PVL $\left(M_{\mathrm{n}}=\sim 830\right)$ and PCL $\left(M_{\mathrm{n}}=\sim 930\right)$ under the conditions same as those toward polyethers described above (Scheme 1b). The precipitated product was isolated and its XRD pattern shows two diffraction peaks at $2 \theta=12.8$ and $19.8^{\circ}$, corresponding to $d=0.70$ and $0.45 \mathrm{~nm}$, respectively (Figure 1), indicating that the product is an inclusion complex composed of amylose and polyester.

Figure 2 shows the ${ }^{1} \mathrm{H}$ NMR spectra of the employed mixture of the guest polyesters $\left(\mathrm{CDCl}_{3},(\mathrm{a})\right)$ and the product obtained by the vine-twining polymerization (DMSO- $d_{6}$, (b)). The unit ratio of PVL/PCL in feed was assessed to be 1.00:0.92 on the basis of the integrated ratio of the signal $\mathbf{e}$ due to both PVL and PCL to the signal a due to only PCL (Figure 2a and Run 1 in Table I). In the ${ }^{1} \mathrm{H}$ NMR spectrum of the product, the signals due to PVL and amylose are observed, whereas no signals due to PCL appear, indicating that amylose has selectively included PVL (Figure $2 \mathrm{~b}$ and Run 1 in Table I). The selectivity of the inclusion toward two resemblant polyethers by amylose in the vine-twining polymerization was not perfect as described above, ${ }^{3 \mathrm{~g}}$ whereas amylose 
Table I. Selectivity on Inclusion of Amylose toward PVL and PCL in the Vine-Twining Polymerization ${ }^{\mathrm{a}}$

\begin{tabular}{|c|c|c|c|c|c|}
\hline \multirow{2}{*}{ Run } & \multirow{2}{*}{$\frac{\text { Unit ratio in feed }^{b}}{\mathrm{PVL} / \mathrm{PCL}}$} & \multicolumn{2}{|c|}{ Feed amount (mmol [mg]) } & \multirow{2}{*}{$\begin{array}{l}\text { Yield } \\
\text { (mg) }\end{array}$} & \multirow{2}{*}{$\begin{array}{c}\text { Unit ratio in the product }{ }^{\mathrm{b}} \\
\mathrm{PVL} / \mathrm{PCL} / \text { amylose }\end{array}$} \\
\hline & & $\mathrm{G}_{7}$ & G-1-P & & \\
\hline 1 & $1.00: 0.92$ & $4.0 \times 10^{-4}[0.5]$ & $0.1[30.4]$ & 6.6 & $1.00: 0: 5.72$ \\
\hline 2 & $1.00: 2.57$ & $4.0 \times 10^{-4}[0.5]$ & $0.1[30.4]$ & 6.8 & $1.00: 0.14: 3.16$ \\
\hline 3 & $1.00: 4.88$ & $4.0 \times 10^{-4}[0.5]$ & $0.1[30.4]$ & 6.7 & $1.00: 0.25: 5.26$ \\
\hline 4 & $1.00: 0.92$ & $2.0 \times 10^{-3}[2.3]$ & $0.5[152.1]$ & 20.2 & $1.00: 0: 5.45$ \\
\hline 5 & $1.00: 0.92$ & $6.0 \times 10^{-3}[6.9]$ & $1.5[456.2]$ & 54.4 & $1.00: 0.26: 6.57$ \\
\hline 6 & $1.00: 0.92$ & $1.2 \times 10^{-2}[13.8]$ & 3.0 [912.3] & 147.0 & $1.00: 0.46: 8.95$ \\
\hline
\end{tabular}

a Polymerization was carried out in the presence of mixtures of PVL $(0.3 \mathrm{mmol}$ unit $=30.0 \mathrm{mg})$ and $\mathrm{PCL}(0.3 \mathrm{mmol}$ unit $=34.0 \mathrm{mg}$ ) (for Run $1,4-6)$ catalyzed by phosphorylase (16 unit) in sodium acetate buffer $(0.2 \mathrm{~mol} / \mathrm{L}, \mathrm{pH}=6.2, \mathrm{ca} .5 \mathrm{~mL}$ ) for $6 \mathrm{~h}$ at $40-45^{\circ} \mathrm{C}$. ${ }^{\mathrm{b}}$ Estimated by ${ }^{1} \mathrm{H}$ NMR measurements.

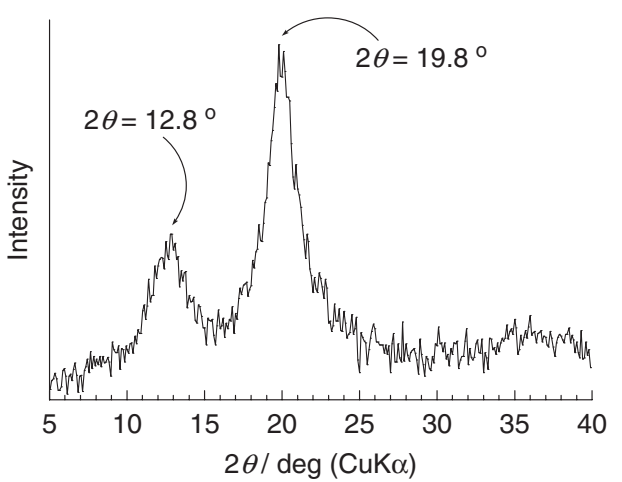

Figure 1. XRD pattern of the product (Run 1 in Table I).

selectively included only PVL from a mixture of two resemblant polyesters. On the basis of the present and the following previous results in the vine-twining polymerization, we assumed that the inclusion ability of amylose toward PCL is lower than that of PVL, POXT, and PTHF. As previously reported, both POXT and PTHF with molecular weight of $c a$. 4000 were included in the cavity of amylose by the vinetwining polymerization. ${ }^{3 c}$ Moreover, PVLs with molecular weights of 2000-5000 were included in the cavity of amylose by the vine-twining polymerization, but PCLs with similar molecular weights did not form inclusion complexes with amylose by the same method. ${ }^{3 d}$

When the unit ratio of PCL in feed was increased in the mixture of the guest polyesters, amylose came to include PCL (Run 2 and 3 in Table I). However, the unit ratio of PCL in the included polyesters was obviously lower than that in feed. When the enzymatic polymerization was carried out in higher concentrations of G-1-P and $\mathrm{G}_{7}$, amylose included both PVL and PCL upon increasing the yield of the products (Runs 5 and 6 in Table I). Such tendency is same as that by using mixtures of POXT/PTHF as described above. ${ }^{3 g}$ We supposed that amylose started to include PCL at a later stage of the polymerization, because of decreasing the concentration of PVL with the progress of the polymerization due to the predominant inclusion. Therefore, we investigated the timecourse for selectivity on inclusion of amylose toward PVL and PCL under the conditions of Run 6 in Table I. Although amylose almost selectively included PVL for the times up to $5 \mathrm{~min}$, it started to include both the guest polymers for the
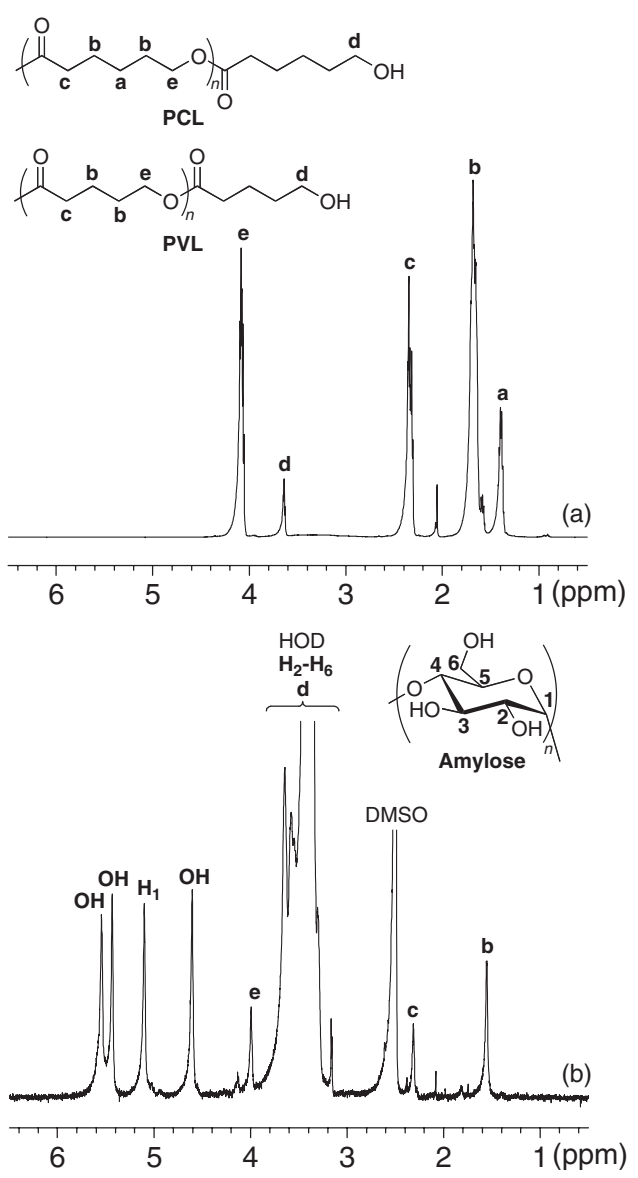

Figure 2. ${ }^{1} \mathrm{H}$ NMR spectra of (a) the mixture of $\mathrm{PVL} / \mathrm{PCL}$ in $\mathrm{CDCl}_{3}$ and (b) the product obtained by vine-twining polymerization in DMSO- $d_{6}$ (Run 1 in Table I).

further reaction times (Figure 3). In addition, we investigated the time-course for the ratio of PCL to PVL in the filtrate of the reaction solution. Consequently, we found that the PCL/PVL ratio increased for the times up to $5 \mathrm{~min}$ and gradually decreased after this time (Figure 3). These results indicated that amylose predominantly included PVL at the initial stage of the polymerization, leading to degreasing the concentration of PVL in the reaction solution. Then, amylose possibly started to include PCL at the later stage of the polymerization. 


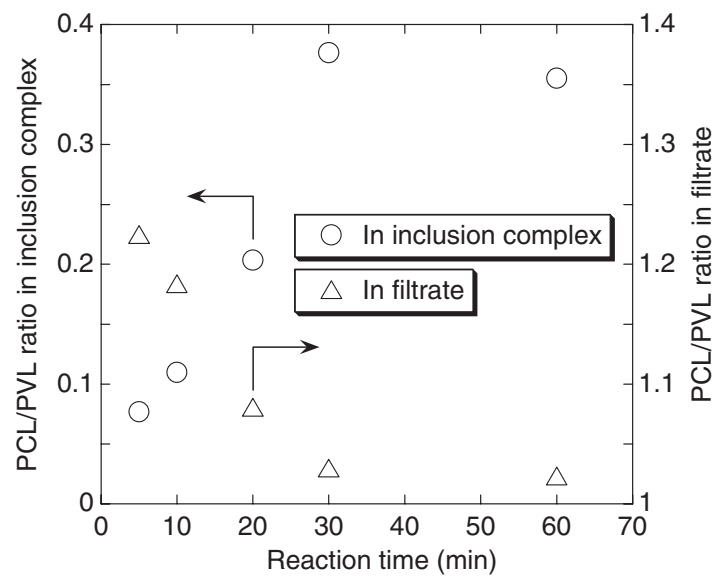

Figure 3. Time-course curves for the $\mathrm{PCL} / \mathrm{PVL}$ ratios in the inclusion complexes and in the filtrates of the reaction solution. These values were calibrated by dividing the $\mathrm{PCL} / \mathrm{PVL}$ ratios in the inclusion complexes and in the filtrates by those in feed, respectively.

Evaluation of Priority on Inclusion of Amylose among POXT, PTHF, PVL, and PCL

As aforementioned, amylose exhibited the selectivity on inclusion toward aliphatic polyethers and polyesters in the vine-twining polymerization. On the basis of these results, we have supposed that there is a difference in the inclusion ability of amylose toward all guest polymers used above. To evaluate the priority on inclusion of amylose among POXT, PTHF, PVL, and PCL, the vine-twining polymerization was carried out using mixtures of all combinations of two guest polymers chosen among them.

As previously reported, PVL, POXT, and PTHF with molecular weights of $c a .2000$ were individually included in the cavity of amylose by the vine-twining polymerization but PCL with similar molecular weight did not form inclusion complex with amylose, whereas the inclusion complexes were formed well, respectively, from all the guest polymers with molecular weights of $c a$. 1000 by the vine-twining polymerization. Because we would like to evaluate priority on inclusion of amylose among the guest polymers with similar molecular weights, we employed the guest polymers with molecular weight of $c a .1000$ for the following investigations.

Because amylose selectively included PTHF and PVL from the mixtures of PTHF/POXT and PVL/PCL, respectively, in the vine-twining polymerization, it is expected that the aliphatic polymers having 4 methylene units are more favorable as the guest compounds to form the inclusion complexes with amylose than those of other numbers. Based on such our interesting as which polymer amylose selectively includes from a mixture of PTHF/PVL, the vine-twining polymerization using this mixed system was first investigated.

Figure 4 shows the ${ }^{1} \mathrm{H}$ NMR spectra of the employed mixture of PTHF/PVL $\left(\mathrm{CDCl}_{3}\right.$, (a)) and the product obtained by the vine-twining polymerization (DMSO- $\left.d_{6},(\mathrm{~b})\right)$. The unit ratio of $\mathrm{PTHF} / \mathrm{PVL}$ in feed was assessed to be 1.00:0.86 on the basis of the integrated ratio of the signal a due to both PTHF

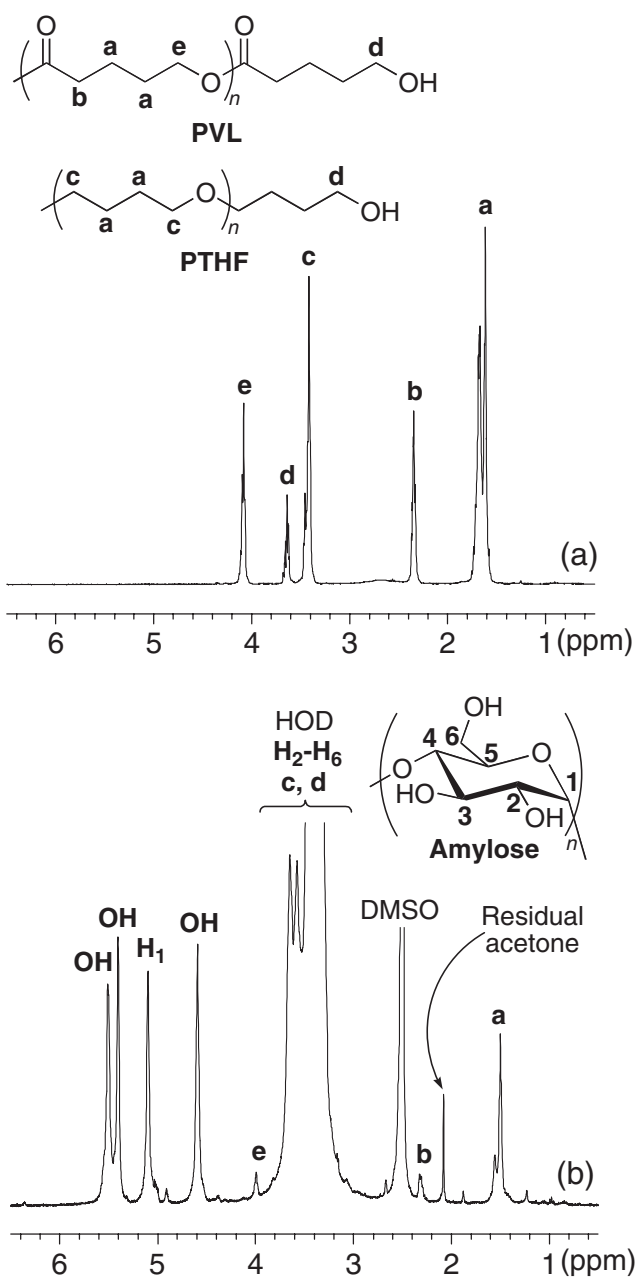

Figure 4. ${ }^{1} \mathrm{H}$ NMR spectra of (a) the mixture of $\mathrm{PTHF} / \mathrm{PVL}$ in $\mathrm{CDCl}_{3}$ and (b) the product obtained by vine-twining polymerization in DMSO- $d_{6}$

Table II. Evaluation of Priority on Inclusion of Amylose among POXT, PTHF, PVL, and PCL in Vine-Twining Polymerization ${ }^{\mathrm{a}}$

\begin{tabular}{ccccc}
\hline Run & $\begin{array}{c}\text { Mixture of guest } \\
\text { polymers }\end{array}$ & $\begin{array}{c}\text { Unit ratio } \\
\text { in feed }\end{array}$ & Yield $(\mathrm{mg})$ & $\begin{array}{c}\text { Unit ratio } \\
\text { in the product }\end{array}$ \\
\hline 1 & PTHF/PVL & $1.00: 0.86$ & 3.0 & $1.00: 0.29$ \\
2 & PTHF/PCL & $1.00: 0.82$ & 3.3 & $1.00: 0$ \\
3 & POXT/PCL & $1.00: 0.92$ & 2.5 & $1.00: 0.07$ \\
4 & POXT/PVL & $1.07: 1.00$ & 3.0 & $0.79: 1.00$ \\
5 & POXT/PTHF & $1.13: 1.00$ & 3.3 & $0.08: 1.00$ \\
6 & PVL/PCL & $1.00: 0.92$ & 6.6 & $1.00: 0$ \\
\hline
\end{tabular}

aPolymerization conditions: phosphorylase; 16 unit, $\mathrm{G}_{7} ; 4.0 \times 10^{-4}$ $\mathrm{mmol}=0.5 \mathrm{mg}, \mathrm{G}-1-\mathrm{P} ; 0.1 \mathrm{mmol}=30.4 \mathrm{mg}$, guest polymer; $0.3 \mathrm{mmol}$ unit, molecular weights of the employed guest polymers estimated by ${ }^{1} \mathrm{H}$ NMR measurements; 940 for POXT, 970 for PTHF, 830 for PVL, and $\sim 930$ for $\mathrm{PCL}$, reaction time; $6 \mathrm{~h}$, reaction temperature; $40-45^{\circ} \mathrm{C}$. ${ }^{b}$ Estimated by ${ }^{1} \mathrm{H}$ NMR measurements.

and PVL to the signal e due to only PVL (Figure 4a and Run 1 in Table II). In the ${ }^{1} \mathrm{H}$ NMR spectrum of the product, the unit ratio of PTHF/PVL changed to be 1.00:0.29 compared with their feed ratio (Figure $4 \mathrm{~b}$ and Run 1 in Table II), indicating that amylose preferably included PTHF. However, amylose did not exhibit the definite selectivity on inclusion toward PTHF 


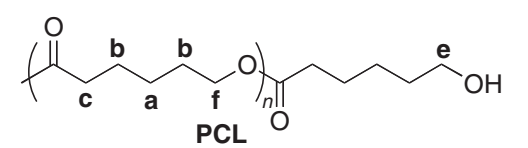
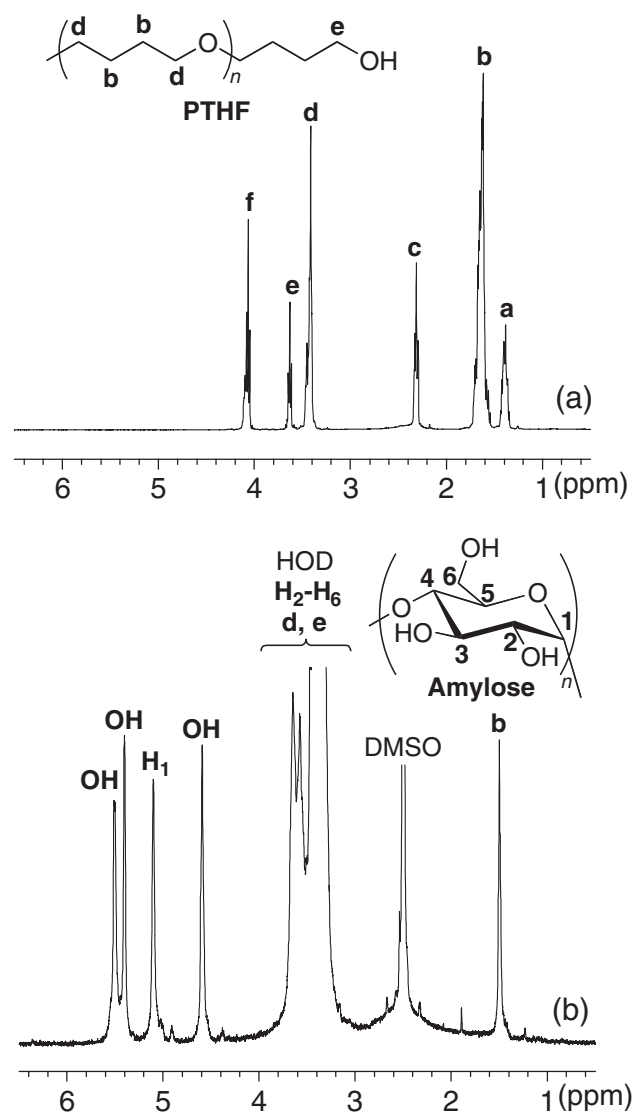

Figure 5. ${ }^{1} \mathrm{H}$ NMR spectra of (a) the mixture of PTHF/PCL in $\mathrm{CDCl}_{3}$ and (b) the product obtained by vine-twining polymerization in DMSO- $d_{6}$.

and PVL. This is probably because that the difference in hydrophobicity of PTHF and PVL would not be so worth affecting the inclusion by amylose.

In addition, we also investigated the vine-twining polymerization using mixtures of other combinations of two guest polymers. In the case of using the mixture of PTHF/PCL, the unit ratio of PTHF/PCL in feed was assessed to be 1.00:0.82 on the basis of the integrated ratio of the signal $\mathbf{b}$ due to both PTHF and PCL to the signal $\mathbf{f}$ due to only PCL (Figure 5a and Run 2 in Table II), whereas their unit ratio in the product obtained by the vine-twining polymerization was estimated to be 1.00:0 (Figure 5b and Run 2 in Table II), indicating that amylose selectively included PTHF. When the mixture of POXT/PCL was employed for this polymerization system, amylose almost selectively included POXT (Figure 6 and Run 3 in Table II). As described above, amylose selectively included PVL from the mixture of PVL/PCL in the vinetwining polymerization (Figure 2 and Run 6 in Table II). All the above results indicate that the inclusion ability of amylose toward PCL is the lowest among the guest polymers employed in this study. We investigated further the vine-twining polymerization using a mixture of POXT/PVL, and found
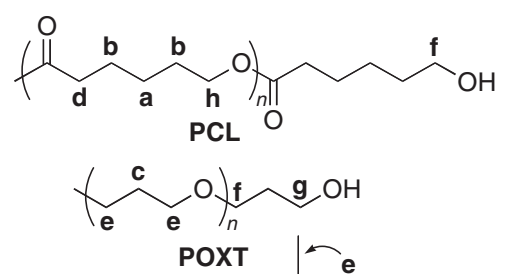

(a)

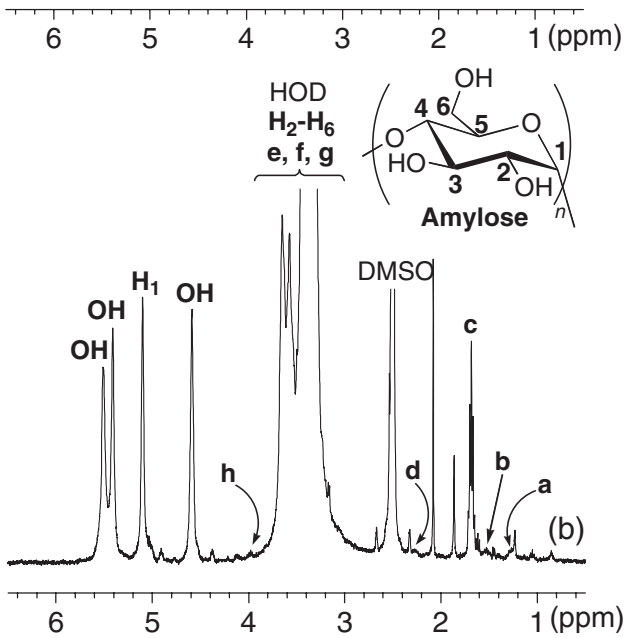

Figure 6. ${ }^{1} \mathrm{H}$ NMR spectra of (a) the mixture of POXT/PCL in $\mathrm{CDCl}_{3}$ and (b) the product obtained by vine-twining polymerization in DMSO- $d_{6}$.

that amylose preferred to include PVL (Figure 7 and Run 4 in Table II). In addition, amylose almost selectively included PTHF from a mixture of POXT/PTHF with molecular weights of $c a .900$ (Figure 8 and Run 5 in Table II), which was almost same as the result in the case of using them with relatively higher molecular weights as described above. ${ }^{3 g}$ On the basis of all results, we concluded that the priority on inclusion of amylose toward the guest polymers employed in this study in the vine-twining polymerization was $\mathrm{PTHF}>\mathrm{PVL}>$ POXT > PCL.

Finally, we investigated whether $\mathrm{G}_{7}$ interacted with guest polymers, e.g., PTHF in the aqueous solution by following experiment. After PTHF $(21.6 \mathrm{mg}=0.3 \mathrm{mmol})$ was suspended in water $(5 \mathrm{~mL})$ using an ultrasonic wave, $\mathrm{G}_{7}(4.0 \mathrm{mg}=$ $3.5 \mu \mathrm{mol}$ ) was added into this suspension and it was stirred vigorously for $5 \mathrm{~min}$ at $\mathrm{ca} .40^{\circ} \mathrm{C}$. The suspension was evaporated and acetone as a good solvent for PTHF was added to the residue. The acetone-insoluble fraction was collected by filtration, washed with acetone, and dried under reduced pressure at room temperature to yield the product. In the ${ }^{1} \mathrm{H}$ NMR spectrum of the product, the signals due to PTHF and $\mathrm{G}_{7}$ were observed, indicating that $\mathrm{G}_{7}$ interacted with PTHF in 


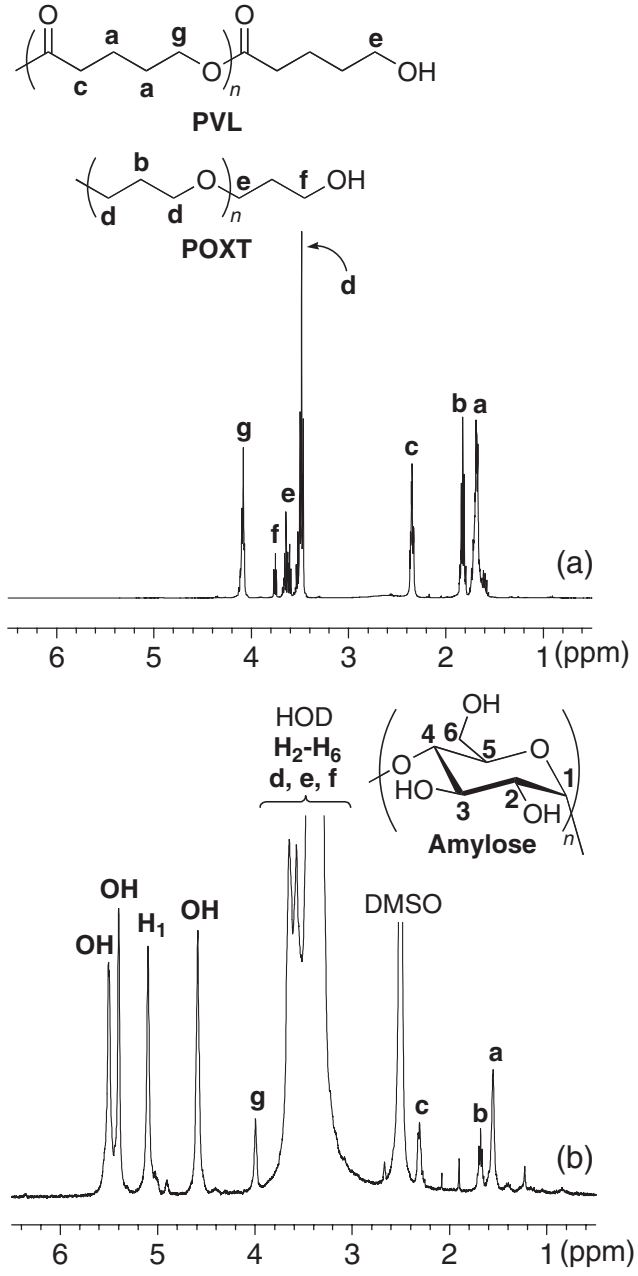

Figure 7. ${ }^{1} \mathrm{H}$ NMR spectra of (a) the mixture of POXT/PVL in $\mathrm{CDCl}_{3}$ and (b) the product obtained by vine-twining polymerization in DMSO- $d_{6}$.

the aqueous solution. The above result indicated that in the vine-twining polymerization, the interaction of $\mathrm{G}_{7}$ primer with guest polymers in the initial stage of the system might be a key step for the formation of the amylose-polymer inclusion complexes.

\section{CONCLUSIONS}

In this paper, we described that amylose selectively included PTHF or PVL from a mixture of two resemblant polyethers or a mixture of two resemblant polyesters, respectively, in the vinetwining polymerization. In addition, we found that the priority on inclusion of amylose toward the above-mentioned guest polymers in the vine-twining polymerization was PTHF > PVL $>$ POXT $>$ PCL. The hydrophobicities of the polymers probably affected the inclusion ability of amylose.

Acknowledgment. This work was supported in part by a fund from Sekisui Chemical Co., Ltd. and a Grant-in-Aid for Scientific Research from Ministry of Education, Culture, Sports, Science, and Technology, Japan (No. 19550126). We
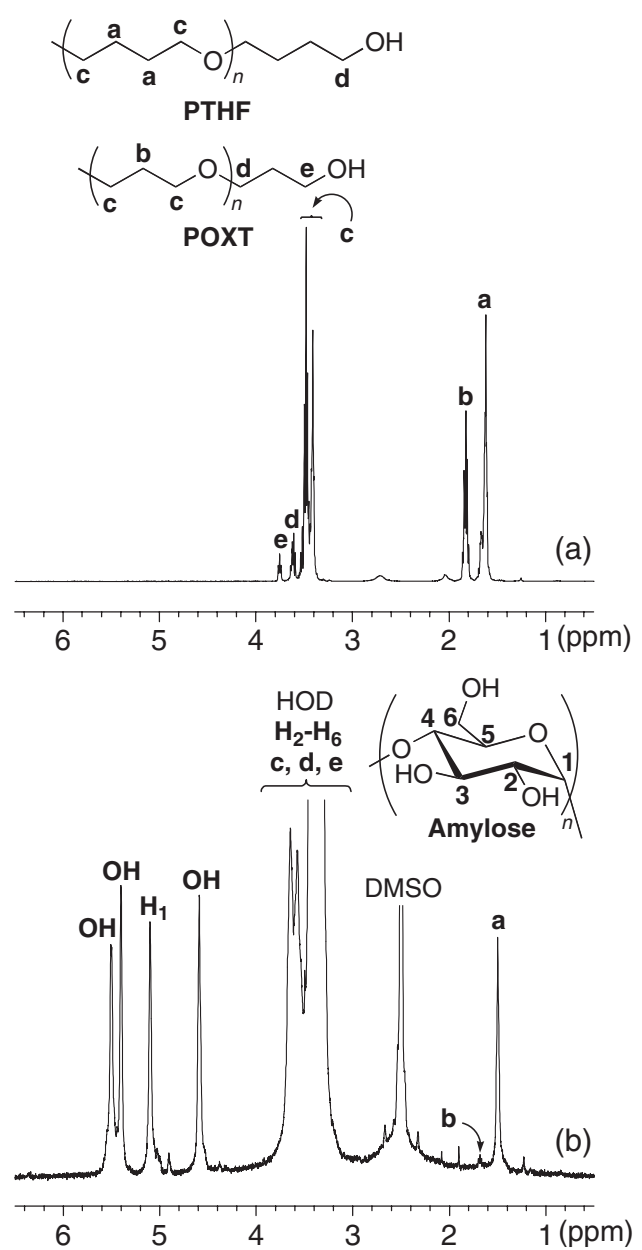

Figure 8. ${ }^{1} \mathrm{H}$ NMR spectra of (a) the mixture of POXT/PTHF in $\mathrm{CDCl}_{3}$ and (b) the product obtained by vine-twining polymerization in DMSO$d_{6}$.

acknowledge the gift of phosphorylase from Ezaki Glico Co. Ltd., Osaka, Japan.

Received: October 9, 2008 Accepted: December 22, 2008 Published: February 12, 2009

\section{REFERENCES}

1. Stryer, L. "Biochemistry," W. H. Freeman \& Company, New York, 1995.

2. a) T. Serizawa, T. Sawada, H. Matsuno, T. Matsubara, and T. Sato, J. Am. Chem. Soc., 127, 13780 (2005).

b) T. Serizawa, T. Sawada, and T. Kitayama, Angew. Chem., Int. Ed., 46, 723 (2007).

c) T. Date, K. Tanaka, T. Nagamura, and T. Serizawa, Chem. Mater., 20, 4536 (2008).

3. a) J. Kadokawa, Y. Kaneko, H. Tagaya, and K. Chiba, Chem. Commun., 449 (2001).

b) J. Kadokawa, Y. Kaneko, A. Nakaya, and H. Tagaya, Macromolecules, 34, 6536 (2001).

c) J. Kadokawa, Y. Kaneko, S. Nagase, T. Takahashi, and H. Tagaya, Chem. Eur. J., 8, 3321 (2002).

d) J. Kadokawa, A. Nakaya, Y. Kaneko, and H. Tagaya, Macromol. 
Chem. Phys., 204, 1451 (2003).

e) Y. Kaneko and J. Kadokawa, Chem. Rec., 5, 36 (2005).

f) Y. Kaneko and J. Kadokawa, J. Biomater. Sci., Polym. Ed., 17, 1269 (2006)

g) Y. Kaneko, K. Beppu, and J. Kadokawa, Biomacromolecules, 8, 2983 (2007).

h) Y. Kaneko, K. Beppu, and J. Kadokawa, Macromol. Chem. Phys., 209, 1037 (2008).

i) Y. Kaneko, Y. Saito, A. Nakaya, J. Kadokawa, and H. Tagaya, Macromolecules, 41, 5665 (2008).

4. a) O. K. Kim, L. S. Choi, H. Y. Zhang, X. H. He, and Y. H. Shih, J. Am. Chem. Soc., 118, 12220 (1996).

b) L. S. Choi and O. K. Kim, Macromolecules, 31, 9406 (1998).

c) T. Sanji, N. Kato, M. Kato, and M. Tanaka, Angew. Chem., Int. Ed., 44, 7301 (2005).

d) I. Lalush, H. Bar, I. Zakaria, S. Eichler, and E. Shimoni, Biomacromolecules, 6, 121 (2005).

e) T. Sanji, N. Kato, and M. Tanaka, Macromolecules, 39, 7508 (2006).

f) O. K. Kim, J. Je, and J. S. Melinger, J. Am. Chem. Soc., 128, 4532 (2006).

g) T. Sanji, N. Kato, and M. Tanaka, Org. Lett., 8, 235 (2006).

5. a) R. L. Shogren, R. V. Green, and Y. V. Wu, J. Appl. Polym. Sci., 42, 1701 (1991).

b) R. L. Shogren, Carbohydr. Polym., 22, 93 (1993).

c) A. Star, D. W. Steuerman, J. R. Heath, and J. F. Stoddart, Angew. Chem., Int. Ed., 41, 2508 (2002).

d) M. Ikeda, Y. Furusho, K. Okoshi, S. Tanahara, K. Maeda, S. Nishino, T. Mori, and E. Yashima, Angew. Chem., Int. Ed., 45, 6491 (2006).

e) T. Kida, T. Minabe, S. Okada, and M. Akashi, Chem. Commun., 1559 (2007).
6. The enzymatic polymerization is a useful tool for the regio- and stereocontrolled preparation of polysaccharides: a) S. Kobayashi, H. Uyama, and S. Kimura, Chem. Rev., 101, 3793 (2001).

b) S. Shoda, R. Izumi, and M. Fujita, Bull. Chem. Soc. Jpn., 76, 1 (2003).

c) S. Kobayashi, M. Ohmae, S. Fujikawa, and H. Ochiai, Macromol. Symp., 226, 147 (2005).

d) S. Kobayashi and M. Ohmae, Adv. Polym. Sci., 194, 159 (2006).

For example, phosphorylase-catalyzed enzymatic polymerization using G-1-P proceeds with the regio- and stereoselective construction of an $\alpha$-glycosidic bond under mild conditions, leading to the direct formation of amylose in aqueous media. This polymerization is initiated from a maltooligosaccharide primer such as $G_{7}$. Then, the propagation proceeds through the following reversible reaction to produce a $(1 \rightarrow 4)$ - $\alpha$-glucan chain, i.e., amylose:

$$
[(\alpha, 1 \rightarrow 4)-\mathrm{G}]_{n}+\mathrm{G}-1-\mathrm{P} \leftrightarrows[(\alpha, 1 \rightarrow 4)-\mathrm{G}]_{n+1}+\mathrm{P}
$$

In the reaction, a glucose unit is transferred from G-1-P to the nonreducing $4-\mathrm{OH}$ terminus of a $(1 \rightarrow 4)$ - $\alpha$-glucan chain, resulting in inorganic phosphate $(\mathrm{P})$.

e) G. Ziegast and B. Pfannemüller, Carbohydr. Res., 160, 185 (1987)

7. M. Yanase, H. Takata, K. Fujii, T. Takaha, and T. Kuriki, Appl. Environ. Microbiol., 71, 5433 (2005).

8. a) H. Desai, A. V. Cunliff, M. J. Stewart, and A. J. Amass, Polymer, 34, 642 (1993).

b) S. Smith and A. J. Hubin, J. Macromol. Sci., Chem., 7, 1399 (1973).

9. N. Nomura, A. Taira, T. Tomioka, and M. Okada, Macromolecules, 33, 1497 (2000).

10. V. V. Braunmühl, G. Jonas, and R. Stadler, Macromolecules, 28, 17 (1995). 